\title{
Cambios en el Tratamiento de la Infertilidad Durante los tres pasados Decenios"
}

\author{
Por E. C. Hamblen, M.D., F.A.C.S., Durham, N.C., U.S.A. \\ Del Departamento de Obstetricia y Ginecología, \\ Duke University Medical Center
}

"Sin prolegómenos permítasenos preguntar: ¿Cuáles son las condiciones esenciales para la concepción?

1 - Ella ocurre durante la vida menstrual.

2 - La menstruación debe ser tal, que refleje un saludable estado de la cavidad uterina.

3 - Los orificios y el canal cervical deben estar suficientemente abiertos para permitir la libre salida del flujo menstrual y también para admitir la entrada del espermatozoide.

4 - El cuello uterino debe ser de forma, figura, tamaño y densidad apropiados.

5 - El útero debe estar en posición normal, esto es, no debe encontrarse en grado máximo de anteversión ni en retroversión.

6 - La vagina debe ser capaz de recibir y retener el fluído espermático.

7 - El semen, conteniendo espermatozoides vivos, debe ser depositado en la vagina en un tiempo adecuado.

8 - Las secreciones del cérvix y vagina no deben matar al espermatozoide".

J. Marion Sims: Clinical Notes on Uterine Surgery with Special Reference to the Management of the Sterile Condition, William \& Co., Publishers, New York, 1873.

* Presentado al Congreso Regional de "The International Fertility Association", Acapulco, México, Enero 28-31, 1961. y a la Universidad de Antioquia. Facultad de Medicina, Medellín, Colombia, Febrero 10, 1961. 
Los tres pasados decenios han estado especialmente dedicados al estudio y perfeccionamiento de métodos que aseguren y mantengan vigentes los ocho postulados esenciales de SIMS, para la concepción.

Han sido desarrolladas mejores técnicas de diagnóstico que se han incorporado a nuevos sistemas de tratamiento.

Este camino ha sido preparado por un conocimiento más profundo de los cónyuges, en materias genesiológicas y una discusión más franca sobre estas cuestiones que día a día aparecen en libres y revistas.

Actualmente, muchos más médicos buscan la manera de ayudar a estas parejas, porque ahora ellos han recibido un mejor entrenamiento y porque el estudio y culminación de estos objetivos constituye una respetable rama de la medicina. Esto no fue considerado así en los días de SIMS.

Por consiguiente, las parejas estériles encuentran un auxilio competente y cercano a ellas sin tener que recurrir a distantes centros médicos.

Han ocurrido otros progresos intangibles pero no obstante reales, en fertilidad. Matrimonios antes de alcanzar la "mayoría de edad" son ahora comunes y las familias numerosas están otra vez de moda. Estos factores surgidos de la segunda guerra mundial han persistido y han sido el origen de nuestra extraordinaria rata de nacimientos. Se presta a serias dudas que los adelantos en nutrición o el uso indiscriminado de vitaminas hayan jugado un papel importante en nuestro aumento de población.

\section{$L A$ ESPOSA}

La esposa ha participado más ampliamente que su marido de los adelantos científicos de las tres últimas décadas. Esto es debido en gran parte al hecho de que los ginecólogos están mucho más interesados que los urólogos en los problemas de fertilidad y también a que se encuentran relativamente pocos endocrinólogosandrólogos en comparación a los muchos endocrinólogos-ginecólogos.

OVARIOS: Se ha adelantado mucho sobre los conocimientos de la fisiología ovárica, sus hormonas y los métodos para la determinación cuantitativa de ellas. El empleo de la temperatura ba- 
sal del cuerpo, provee un método relativamente fácil para establecer la ocurrencia de la ovulación al mismo tiempo que nos suministra con bastante aproximación el dato de cuando ella ha sucedido. La determinación de las gonadotropinas urinarias nos da poca información en cuanto a la fecha de la ovulación. Lo mismo rige para la cristalización en helecho del moco cervical. Es posible que en el futuro encontremos algún método eléctrico para verificarla con exactitud. Los estudios culdoscópicos nos suministran datos auxiliares sobre la patología ovárica.

En resumen, actualmente no disponemos de ningún método en que nosotros podamos confiar con seguridad sobre la fecha específica de la ovulación.

La evolución del trataiento conservativo de la hemorragia funcional uterina asociada a ciclos anovulatorios con el empleo de estrógenos y progesterona o de progesterona aislada, nos ha servido para descartar otras terapéuticas que empeoraban el funcionamiento ovárico o conferían una absoluta y permanente esterilidad.

El tratamiento quirúrgico por resección en cuña de los ovarios en pacientes que sufren del así llamado síndrome de STEINLEVENTHAL, ha permitido el embarazo, pero en manos de cirujanos complacientes, ha dado lugar también a muchas laparotomías innecesarias.

El advenimiento de la cortisona y sus derivados y su aplicación terapéutica para la amenorrea y virilización debidos a hiperplasia adrenocortical, ha dado lugar a ciclos ovulatorios y embarazos.

Se oye ahora relativamente poco acerca de la terapia en dosis bajas de rayos $\mathrm{X}$, de los ovarios y de la pituitaria, o solamente de esta última glándula. para inducir la ovulación. También es cierto, que día a día, llegamos a ser más conscientes acerca del posible daño que pueda resultar de cualquier exposición de los ovarios a los rayos ROENTGEN, ya sea incidentalmente por la fluoroscopia durante la histerosalpingografía o durante la radiopelvimetría.

La aparición de las varias gonadotropinas produjo al principio una falsa esperanza de éxito, no obstante que su aplicación se hizo en forma empírica. Poco después se comprobó que ninguna 
gonadotropina, como regla, produciría ovulación en pacientes con ciclos anovulatorios. Más tarde se demostró que pacientes con anovulación debida a hipofunción pituitaria en asociación con ovarios susceptibles de respuesta, podían lograr el embarazo cuando la FSH y la LH fueran empleadas en forma consecutiva. Se sucedió luego un período de desinterés en este sistema terapéutico, habiéndose recobrado el optimismo en años recientes debido a los escasos estudios practicados empleando la FSH y la LH obtenidas de glándula pituitaria humana.

Muchos clínicos han reconocido la fase progestacional corta y la han tratado apropiadamente con dosis suplementarias de estrógenos y progesterona, subsiguiente a la ovulación.

Creemos que actualmente hay menos tratamientos empíricos con tiroides desecado U.S.P., aunque tenemos algunas dudas de que esta terapia esté siendo enmascarada con el uso frecuente y también empírico del cytomel.

Hemos encontrado en nuestra práctica que muchas mujeres supuestamente estériles, con ciclos menstruales irregulares, no necesitan realmente tratamiento endocrino sino más bien un método práctico para determinar el tiempo propicio para el coito. Por tal razón, los datos obtenidos por el uso inteligente de la temperatura basal del cuerpo, es un medio de gran valor para lograr esta información.

TROMPAS: A medida que nosotros hemos obtenido más conocimientos acerca de la fisiología de las trompas, nos hemos dado cuenta de que la permeabilidad es solamente uno de los factores de la normalidad tubárica. Las trompas pueden ser permeables pero también ser incapaces de recoger el óvulo en el momento de su postura o de propulsar el huevo fertilizado debido a un trastorno de la peristalsis o de la función ciliar. Nosotros podemos diagnosticar una obstrucción tubárica pero no tenemos los medios suficientes para conocer la patología en estas otras áreas. Un tratamiento conservativo de la endometriosis por medio de los agentes progestacionales, solo ocasionalmente ha permitido el embarazo, aunque las trompas se encuentren siempre permeables y la pacinte tenga ciclos ovulatorios. El tratamiento quirúrgico de la oclusión tubárica ejecutado con más habilidad, mejor entrenamiento y técnicas más avanzadas ha tenido por consecuencia el aumento de embarazos. 
El advenimiento de los antibióticos, en particular de la penicilina, ha permitido el tratamiento específico de las infecciones gonocócicas y evitado por consiguiente sus secuelas, salpingitis y obstrucciones tubáricas, en muchas mujeres.

UTERO: Una mayor atención se le presta ahora a la cavidad uterina. La histerografía es un procedimiento importante per se. Ella puede conducirnos al diagnóstico de anomalías congénitas, fibromiomas submucosos, pólipos y sinequias. Con frecuencia, un tratamiento quirúrgico satisfactorio de estas entidades, prepara el camino para el embarazo. Aunque la endometritis tuberculosa no es diagnosticada tan frecuentemente en nuestro país en comparación a otros países del mundo, puede suceder que no sea tan rara como pensamos. Un tratamiento efectivo de la tuberculosis pelviana puede ser posible hoy día y puede habilitar a la mujer para ser madre.

CERVIX: Los últimos tres decenios han traído un conocimiento más claro acerca de la fisiología cervical. El examen postcoito ya no es solamente la prueba que HUHNER y SIMS delinearon sino que evalúa también la preparación adecuada o inadecuada del moco cervical para la recepción del espermatozoide eyaculado. Generalmente ha hakido una desconfianza acerca de las supuestas bondades de duchas o instilaciones antes del coito, como auxiliares de la concepción.

\section{EL MARIDO}

En general debemos acusarnos del grave pecado de que aquellos de nosotros preocupados por los problemas de fertilidad, no hayamos sido capaces de transmitir este interés a nuestros colegas urólogos. Indudablemente, si hubiera más endocrinólogos asociados a urólogos, nosotros hubiéramos hecho más progresos en el tratamiento del varón estéril o de aquel que tiene una baja fertilidad.

Hemos tenido conocimientos progresivos de la fisiología y patología testicular. Hemos tenido también diagnósticos más exactos de los varios síndromes asociados con el hipogonadismo. Tenemos mejores métodos de biometría seminal. Hemos aprendido el papel que juega la ocitocina en la dirección del curso y velocidad del espermatozoide durante los trayectos que recorre. Se ha dado más énfasis sobre los resultados satisfactorios del tratamiento de 
la sriptorquidia, más con el fin de prevenir la esteril:dad que de corregir la posición de los testículos.

Se ha alcanzado algún éxito en el tratamiento de individuos con recuento bajo de espermatozoides, con la llamada terapéutica de rebote a base de testosterona. La terapia con gonadotropinas ha sido demasiado desalentadora en el tratamiento de la deficiencia o ausencia de espermatozoides.

A veces la hiperplasia adrenocortical se ha diagnosticado en individuos extremadamente viriles, con recuentos bajos de espermatozoides o con azoospermia y con elevación de los 17 ketústeroides urinarios. Estos pacientes han mejorado su fertilidad con tratamiento a base de cortisona o de sus derivados.

Se escucha ahora menos clamor acerca de la inseminación artificial empleando un donador. Es posible que este método se esté practicando igual que antes pero sus preconizadores no son tan vehementes. La sigla AID (Artificial Insemination Donor) indudablemente no ha engañado a nadie que tenga escrúpulos éticos, religiosos o morales contra este procedimiento.

\section{EL FUTURO}

Nosotros no tratamos de predecir el futuro pero tenemos esperanzas en él. Algunas de éstas son:

Mejores métodos para el tratamiento de la insuficiencia ovárica. lación.

Un método exacto para la determinación de la fecha de ovu-

Métodos que permitan una completa evaluación de la función tubárica.

Más realizaciones en el campo de la endocrinología andrológica.

Una mejor comprensión de la tan llamada "pareja sana estéril". 